\title{
Ferramentas de criação aplicadas em Curso Piloto de Sistema Produto+Serviço (PSS)
}

Creation tools applied in the Pilot Course of Product + Service System (PSS)

SILVEIRA, Emanuela Lima; Msc; Universidade Federal do Paraná

manuhsilveira@gmail.com

SANTOS, Aguinaldo dos; PhD; Universidade Federal do Paraná

asantos@ufpr.br

\section{Resumo}

O seguinte artigo pretende explorar as ferramentas de criatividades aplicadas em Curso Piloto de Sistema-Produto-Serviço (PSS Product-Service-System), formulado como parte de uma iniciativa da Rede de Aprendizagem sobre Sustentabilidade (LeNS - Learning Network on Sustainability). O artigo tem por objetivo analisar a interação dos estudantes com as ferramentas de criatividade aplicadas na geração de novos PSSs. Em muitas situações, as ferramentas de criatividade existentes direcionadas a produtos são aplicadas na criação de PSSs, no entanto estas nem sempre são adequadas, principalmente para a dimensão de serviços intangíveis, na qual deve-se pensar em toda experiência de uso dos diferentes usuários. O método utilizado neste artigo incluiu levantamento bibliográfico, seguido de estudo de caso exploratório e análise por meio da aplicação de questionário. A pesquisa permitiu analisar as interações com as ferramentas de criatividade aplicadas, a fim de identificar ênfases e lacunas e contribuir com o processo de criação de novos PSSs.

Palavras Chave: Sistema Produto+Serviço; Ferramentas de Criatividade; Curso Piloto LeNS;

\begin{abstract}
The following article intends to explore the applied creativity tools within in the Pilot Course of Product + Service System (PSS), formulated as part of a LeNS-Learning Network on Sustainability initiative. The article aims to analyze the interaction of students with the tools of creativity applied in the generation of new PSSs. In many situations, the existing product-oriented creativity tools are applied in the creation of PSSs, but these are not always adequate, especially for the intangible services dimension, in which one must think of every experience of different users. The method used in this article included a bibliographic survey, followed by exploratory case study and analysis through the application of a questionnaire. The research allowed to analyze the interactions with the applied creativity tools, in order to identify emphases and gaps and contribute to the process of creating new PSSs.
\end{abstract}

Keywords: Product + Service System; Creativity Tools; Lens Pilot Course; 


\section{Introdução}

A criatividade inserida no processo de inovação no serviço é uma das prioridades de pesquisa que têm o potencial de provocar avanço no campo do serviço e beneficiar clientes, organizações e sociedade (OSTROM et al., 2010). Neste contexto Sistemas Produto+Serviço (Product-Service System ou PSS) com destaque à dimensão de Serviço podem se beneficiar da adaptação de métodos de criatividade existentes e ferramentas voltadas para produtos convencionais e design gráfico. No entanto, em muitas situações, essas ferramentas não são capazes de lidar com as interações múltiplas e muitas vezes simultâneas que ocorrem ao longo do desenvolvimento de um serviço e a complexidade de reunir, de forma empática, as perspectivas de várias partes interessadas.

Marilungo et al. (2016) destacam que a abordagem do PSS desloca a atenção do projetista de produzir produtos físicos para oferecer sistemas integrados. Para os autores, idear e projetar um PSS é um processo complexo, que exige múltiplas competências e cooperação entre funções dentro da empresa de fabricação. Kim et al. (2012) também ressaltam que o processo de desenvolvimento do conceito PSS não é simples nem direto. Os autores citam um estudo realizado em que oito de dez empresas apresentaram dificuldades em desenvolver conceitos PSS.

Manzini e Vezzoli (2002) destacam ainda que os projetistas e as organizações enfrentam barreiras na concepção, desenvolvimento, entrega de PSS que incluem a falta de conhecimento e experiência em termos de:

- Métodos e ferramentas de design de serviços;

- Novas ferramentas, que as empresas podem usar para avaliar e implementar PSS;

- Sistemas de gestão de serviços;

- Desenvolvimento e provisão de serviços, e métodos de cálculo de custos do ciclo de vida.

Neste contexto, Pinhanez (2009) afirma que a inovação em PSS na dimensão de serviços baseada em ciência e tecnologia sofre com o descaso em relação à pesquisa e à educação, sendo realizados estudos muito superficiais, e sua prática em grande parte realizada por tentativa e erro. Saco e Gonçalves (2008) demonstram ainda a perspectiva, de acadêmicos e profissionais do setor produtivo, como Design, Engenharia e áreas afins. Existe um amplo consenso de que mesmo que os serviços sejam centrais para a economia, eles nem sempre são tão produtivos e efetivos como deveriam, tendo-se assim uma lacuna no projeto de novos serviços.

A partir dessa premissa, Chu et al. (2010) ressaltam que uma forma de aprofundar as ideias geradas direcionadas a novos PSSs seria por meio de ferramentas de criatividade e da adição de princípios de referência. Os princípios serviriam como dispositivos e exemplos de qualidade a serem seguidos na geração de ideias de maior potencial inovador e na descoberta de um caminho para a resposta de problemas complexos.

O seguinte estudo tem como objetivo avaliar a interação de projetistas iniciantes, com ferramentas de criatividade e a necessidade de implementação de princípios de referência direcionados ao PSS. A pesquisa refere-se a um estudo de caso exploratório realizado com estudantes de Design. O contexto de análise ocorreu dentro de disciplina intensiva (Curso Piloto) de duas semanas (30 horas), ofertada a estudantes de graduação. O Curso Piloto foi formulado 
como parte de uma iniciativa da Rede de Aprendizagem sobre Sustentabilidade (LeNS ${ }^{1}$ Learning Network on Sustainability). Esta rede obteve financiamento do Programa "Erasmust" para implementar um plano de ação sobre o desenvolvimento curricular voltado para a promoção de uma nova geração de designers (educadores e pesquisadores de Design) capazes de desenvolver Design para a Sustentabilidade (DfS -Design for Sustainability), Sistema Produto Serviço Sustentáveis (S.PSS - Sustainable Product-Service Systems) aplicado à Economia Distribuída (DE Distributed Economy).

\section{Sistema Produto+Serviço (PSS) e Design de Serviço}

Um PSS pode ser definido como o resultado de uma estratégia de inovação, que "consiste em uma combinação de produtos tangíveis e serviços intangíveis projetados para que sejam capazes em conjunto de satisfazer as necessidades dos clientes finais" (Tukker e Tischner 2006, p. 1552).

Os PSSs geralmente são agrupados em três tipos: PSS orientado a produtos, PSS orientado a uso e PSS orientado a resultados. O PSS orientado a produtos é um PSS no qual a propriedade de um produto tangível é transferida para clientes, mas os produtores oferecem serviços adicionais, incluindo contratos de manutenção por exemplo. O PSS orientado para o uso é um PSS no qual a propriedade dos produtos é retida pelo provedor do produto e o fornecedor vende as funções dos produtos através dos sistemas de distribuição e pagamento modificados, como compartilhamento, agrupamento e arrendamento. A última categoria proposta por Tukker (2004) é o PSS orientado aos resultados. Nessa possibilidade de PSS existe um acordo entre provedor e cliente, no qual o objetivo é a entrega do resultado combinado e a princípio não há produtos prédeterminados. Uma forma de entregar resultados é a terceirização de um segmento de uma empresa, sendo que outra empresa fica responsável por entregar os resultados necessários. Outra possibilidade é o pagamento por unidade de serviço, em que ainda existe um produto como base porém o usuário compra a saída do produto de acordo com o nível de uso, como no caso das máquinas copiadoras, no qual o cliente compra as cópias como unidade de serviço.

O design de serviço, por sua vez, pode ser definido como uma área de atividade de planejamento e organização de pessoas, infraestrutura, comunicações e recursos de um serviço para melhorar a qualidade e as interações entre consumidores e as organizações (Service Design Network, 2015).

Saco e Gonçalvez (2008) utilizam as seguintes definições para Design de Serviço:

- É uma abordagem centrada no ser humano que se concentra na experiência do cliente e na qualidade do serviço encontro como o valor-chave para o sucesso;

\footnotetext{
1 LeNS (Learning Network on Sustainability) é uma Rede Internacional de Aprendizado de Sustentabilidade (2015-2018), apoiada pela União Européia (ERASMUS +) envolvendo 36 universidades da Europa, Ásia, África, América do Sul e América Central, visando a promoção de uma nova geração de designers (e educadores de design) capazes de contribuir efetivamente para a transição para uma sociedade sustentável para todos. Tem como um de seus objetivos melhorar a acessibilidade do ensino superior em 'Design for Sustainability' (DfS). As atividades do projeto LeNSin envolvem seminários, cursos-piloto, a criação de LeNS Labs regionais e uma plataforma web aberta (descentralizada). Qualquer aluno / designer e professor pode acessar. O projeto centra-se em Sistemas Sustentáveis de Produtos-Serviços (S.PSS) e Economias Distribuídas (DE). Site $<$ http://www.lens.polimi.it/index.php?M1=1\&M=1\&P=p_lensdesc.php.>
} 
- É uma abordagem holística que considera de forma integrada decisões de projeto estratégico, de sistema, de processo e de ponto de contato;

- É um processo sistemático e interativo que integra abordagens e métodos interdisciplinares, orientados para o usuário, em ciclos de aprendizagem contínua, que pretende criar serviços úteis, utilizáveis, desejáveis, eficientes e eficazes.

O objetivo dos métodos de Design de Serviços, deste modo, é projetar de acordo com as necessidades dos usuários e, assim, criar serviços amigáveis, competitivos e relevantes para os consumidores (Service Design Network, 2015).

Apresenta-se na sequência um quadro síntese de todas as ferramentas de criatividades aplicadas na disciplina de PSS, de acordo com plano de trabalho proposto (conforme Quadro 1).

Quadro 1 - Síntese de ferramentas aplicadas a disciplina de PSS

\begin{tabular}{|c|c|}
\hline Ferramentas & Descrição \\
\hline Bodystorming & $\begin{array}{l}\text { Técnica em que designers e outras partes interessadas usam sua expressão corporal para criar ou } \\
\text { representar ideias sobre as interações e configurações em torno de uma determinada experiência. A } \\
\text { técnica permite que situações reais sejam simuladas por pessoas reais, assim uma de suas vantagens é a } \\
\text { possibilidade de feedback imediato sobre como uma idéia específica se encaixaria no contexto alvo } \\
\text { (SEGURA \& VIDAL, 2016; ) }\end{array}$ \\
\hline SDO-MEPSS & $\begin{array}{l}\text { Sustainable Design-Orienting Toolkit (SDO-MEPSS, 2009) integra um roteiro de análise com check-lists que } \\
\text { orientam o Designer na análise das prioridades ambientais, sociais e/ou econômicas.. Esta é uma } \\
\text { ferramenta de apoio ao processo de geração de ideias para Sistemas Produto+Serviço, com base em } \\
\text { princípios do design para a sustentabilidade. A ferramenta está disponível em: <http://www.mepss- } \\
\text { sdo.polimi.it/mepss/website/mepss.html>, sendo que uma versão anterior em português está disponível } \\
\text { no site do NDS: <www.design.ufpr.br/nds>. }\end{array}$ \\
\hline Mapa do Sistema & $\begin{array}{l}\text { O mapa do sistema é uma descrição visual da organização técnica do serviço: os diferentes atores } \\
\text { envolvidos, suas relações mútuas e os fluxos de materiais, energia, informação e dinheiro através do } \\
\text { sistema (SERVICE DESIGN TOOLS, 2014). }\end{array}$ \\
\hline Blueprint & $\begin{array}{l}\text { É uma matriz que representa visualmente, de forma esquemática e simples, o complexo sistema de } \\
\text { interações que caracterizam uma prestação de serviços. Nessa representação, são mapeados os diferentes } \\
\text { pontos de contato do serviço, ou seja, os elementos visíveis e/ou físicos com os quais o cliente interage; as } \\
\text { ações do cliente e de toda a interação com a empresa desde as operações visíveis até aquelas que } \\
\text { ocorrem na retaguarda (SILVA, 2011). }\end{array}$ \\
\hline $\begin{array}{l}\text { Mapa da Jornada } \\
\text { do Usuário }\end{array}$ & $\begin{array}{l}\text { É uma representação gráfica das etapas de relacionamento do cliente com um produto ou serviço, que vai } \\
\text { descrevendo os passos- chave percorridos antes, durante e depois da compra e utilização (SILVA, 2011). }\end{array}$ \\
\hline Matrix DM+PSS & $\begin{array}{l}\text { Diagrama que visualiza áreas potenciais onde a Fabricação Distribuída (DM) pode contribuir para melhorar } \\
\text { o desenvolvimento do PSS. A ferramenta possui um conjunto de } 35 \text { cartões de cenários próximos do } \\
\text { futuro que mostram os potenciais benefícios de aplicar DM ao PSS. Para gerar ideias sobre como os } \\
\text { princípios de DM podem ser integrados no design PSS considerando o ciclo de vida completo do PSS (AINE, } \\
\text { 2016: Disponível em: <http://lens-brazil.org/courses/view/12> }\end{array}$ \\
\hline $\begin{array}{l}\text { Tomorrow } \\
\text { Headline }\end{array}$ & $\begin{array}{l}\text { O Tomorrow Headline consiste em artigos de ficção publicados em revistas que os designers criam. O } \\
\text { artigo 'falso' possibilita uma projeção no futuro a fim de entender o tipo de impacto que o serviço terá } \\
\text { sobre a sociedade. Esta ferramenta também é uma maneira de visualizar a ideia e torná-la mais tangível, }\end{array}$ \\
\hline
\end{tabular}


mais real e mais univocamente percebida entre a equipe e as partes interessadas. (IDEO, 2002) IDEO,

Method Cards, William Stout Architectural Books, São Francisco. Disponível em:

<http://www.servicedesigntools.org/tools/14>

Fonte: SILVA (2011); SEGURA \& VIDAL (2016); <mepss-sdo.polimi.it/mepss>; <servicedesigntools.org>; <lensbrazil.org/course> (2017)

\section{Método de Pesquisa}

O presente estudo segue uma abordagem qualitativa de natureza interpretativa. De acordo com Polaine et al. (2013 p.39), dados quantitativos não traduzem os motivos e razões subjetivas pelos quais as pessoas deixam de usar determinados serviços.

Primeiramente foi elaborada uma fase informacional, em que foi feito o levantamento bibliográfico de conteúdos referentes a: Conceitos PSS e Criatividade; Ferramentas de criatividade direcionadas a PSS na dimensão de Serviço; etc.

No estudo adotou-se um método de pesquisa de estudo de caso exploratório para investigar o problema da pesquisa, com foco na observação direta da utilização das ferramentas de criatividade dentro de uma disciplina de graduação. De acordo com Yin (2004) o estudo de caso exploratório é uma estratégia que visa analisar situações da vida real.

O curso piloto ocorreu entre os dias 16 e 27 de outubro de 2017 no Curso de Graduação em Design da Universidade Federal do Paraná. Com base na experiência de cursos piloto anteriores desenvolvidos no México, África do Sul, China, Índia e Brasil, nos parceiros LeNS, o programa para este Curso Piloto se concentrou em uma seleção de ferramentas-chave que poderiam permitir aos alunos uma introdução ao processo de design de sistemas de produtosserviços.

A coleta de dados consistiu em observações diretas, gravação de vídeo e reunião de documentos produzidos pelos alunos antes, durante e após as sessões de Criatividade.

Na fase de análise, os estudantes, após utilização das ferramentas de criatividade, foram instruídos a responder a um questionário previamente estruturado, registrando suas percepções quanto à metodologia utilizada e a aplicação das ferramentas. A pesquisa propôs-se, desta forma, responder a seguinte pergunta: Qual seria o melhor protocolo para adoção das ferramentas de criatividade para ideação de um novo PSS por projetistas iniciantes?

Os resultados foram confrontados com as proposições obtidas a partir da revisão da literatura, possibilitando o desenvolvimento de diretrizes-chave para professores que pretendem levar essa ferramenta para a sala de aula.

\section{Resultados}

A abordagem didática da disciplina foi baseada na prática. Todos os conteúdos teóricos foram previamente disponibilizados na plataforma LeNS (lens-brazil.org). Incluiu-se slides, vídeo- 
aulas, usando o software Camtasia ${ }^{\circledast}$, estudos de caso, links para vídeos na web, modelos de ferramentas e livros didáticos. A maioria das aulas começou com uma discussão com estudantes para resolver dúvidas quanto 'à teoria do tema do dia'. Esta discussão foi seguida por um período de prática e, no final de cada dia, os alunos foram convidados a apresentar a evolução do seu trabalho através de apresentações de pitch ou discussões abertas (Figura 1).

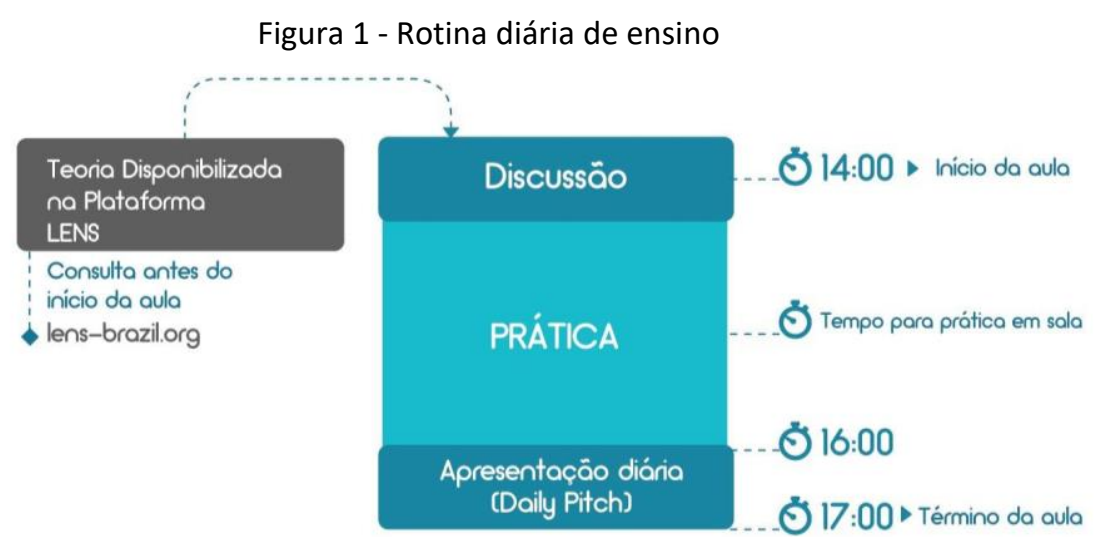

Fonte: adaptado de SANTOS et al. (2018)

Um total de vinte estudantes se inscreveu na disciplina, e doze concluíram todas as atividades previstas na ementa da disciplina. A maioria deles está cursando o terceiro e quarto ano do curso de graduação em Design de Produtos da UFPR. O desafio apresentado aos alunos foi aberto: proposição de soluções inovadoras e visando à sustentabilidade para as pessoas que vivem em cadeiras de rodas na cidade de Curitiba.

Deste modo, no primeiro dia do curso, os alunos receberam informações importantes sobre os desafios enfrentados pelas pessoas em cadeiras de rodas no Brasil, particularmente aquelas com Atrofia Muscular Espinhal. O escopo desta informação também incluiu uma avaliação de mercado sobre a gama de produtos e serviços disponíveis no mercado brasileiro para pessoas em cadeira de rodas. Além desta informação preliminar, foi disponibilizado o contato de uma pessoa em cadeira de rodas que estava disposta a fornecer informações adicionais.

Os estudantes foram divididos em quatro equipes, o que permitiu o desenvolvimento de pesquisas direcionadas especificamente ao tema selecionado por cada uma delas (mobilidade, vestuário, entretenimento e adaptações para novos cadeirantes). Reuniu-se assim informações importantes que permitiram um entendimento inicial sobre os principais problemas enfrentados pelas pessoas em cadeiras de rodas no Brasil.

A preparação, para chegar à fase de ideação, envolveu uma introdução geral aos fundamentos dos Sistemas de Produtos-Serviços e da Economia Distribuída; o desenvolvimento de Personas com base em dados demográficos e da literatura; o desenvolvimento da ferramenta de Mapa do Sistema que representa a situação existente, com a identificação de todas as principais partes interessadas e seus principais fluxos (informação, material, finanças, trabalho); a aplicação da ferramenta Blueprint que representa o status quo da situação existente, incluindo as atuais atividades dos usuários, os principais pontos de contato, bem como os estágios, backstage e serviços de suporte; avaliação ambiental, social e econômica do sistema existente usando as heurísticas do Sustainable Design Orienting Toolkit (SDO). Posteriormente, para o processo de 
ideação deu-se início às sessões de criatividade. Na primeira sessão foram aplicadas ferramentas de interação que incluíram o uso de 35 cartões com cenários de PSS e Economia Distribuída; e na segunda sessão de criatividades foram aplicadas técnicas de Bodystorming e Tomorrow Headlines possibilitando a geração de ideias por meio da prototipagem (Figura 2).

Figura 2 - Programa Geral da Disciplina
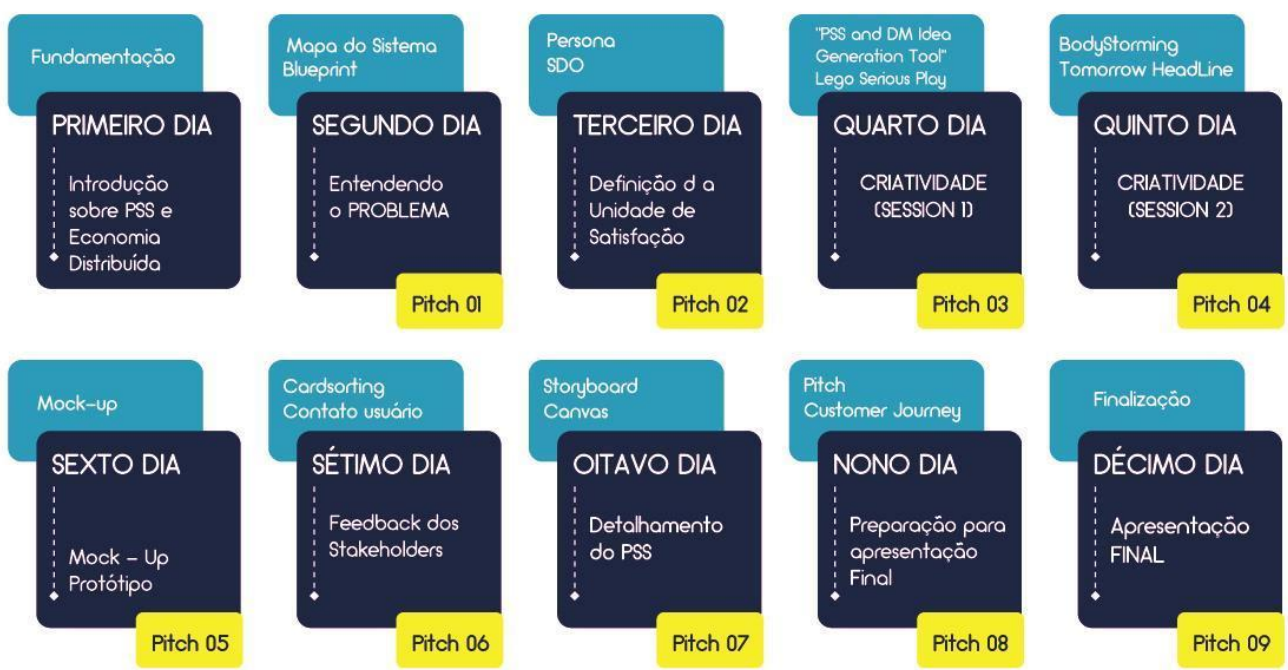

Fonte: adaptado de Santos et al. (2018)

Destacam-se neste artigo as ferramentas elaboradas no dia quatro e cinco nas sessões destinadas ao processo criativo. Cabe destacar que o processo criativo não se deteve apenas a esta fase, entende-se que durante as duas semanas o processo de criação das soluções foi contínuo.

Deste modo a fase de ideação se iniciou no quarto dia, com o uso dos Sistemas de Serviços de Produto para a Ferramenta de Geração de Ideias de Fabricação Distribuída, desenvolvido por Aine Petrulaityte (doutoranda da Universidade de Brunnel) (Figura 3). Esta atividade resultou em uma série de idéias sobre conceitos em PSS / DM e contribuiu para refinar a "unidade de satisfação" adotada por cada equipe de alunos. Os conceitos exploraram todos os tipos de PSS (orientado ao produto, ao uso e ao resultado) e foram orientados para o conceito mais amplo de Economia Distribuída.

Figura 3 - Esquerda foto de aplicação da ferramenta e Matriz presente na ferramenta DM+PSS
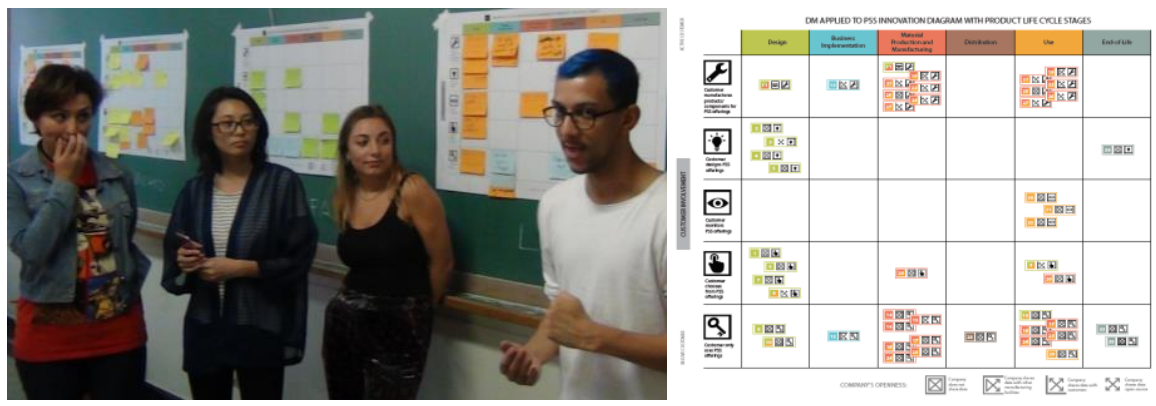

Fonte: Os autores (2017); Petrulaityte (2017). 
No quarto dia também foi aplicada a ferramenta Lego Serious Play ${ }^{\circledR}$ (Figura 4).

Figura 4 - Uso do Lego Serious Play ${ }^{\circledR}$ para representar cenas-chave dos conceitos do sistema

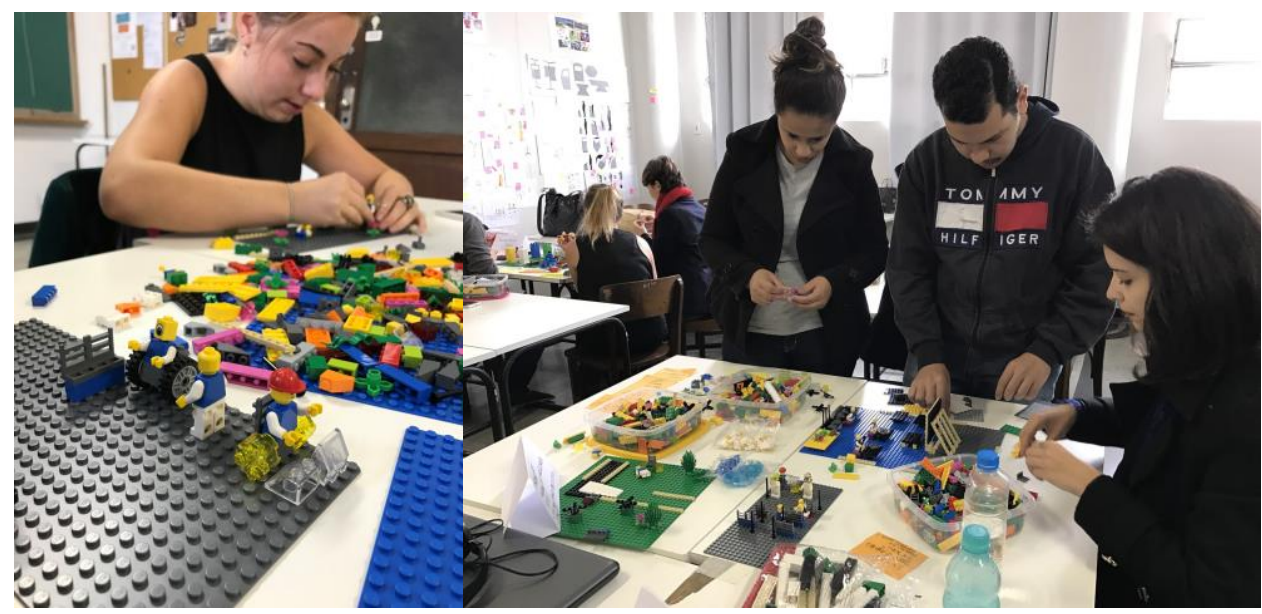

Fonte: Os autores (2017)

A ferramenta foi utilizada em três ciclos de ideação, onde no primeiro ciclo os alunos representavam três cenas de seu conceito; No segundo ciclo, as equipes mudaram de mesa e, então, puderam intervir nos outros conceitos e, finalmente, no terceiro ciclo, a equipe voltaria à sua mesa original e desenvolveria a proposição final. Cada ciclo foi seguido de uma apresentação com todos os estudantes, pode-se assim discutir aspectos bons, falhas e contribuições para as idéias de cada equipe. No ciclo final foram utilizados post-its para que cada equipe sinaliza-se questões que foram esquecidas em cada cenário ou partes do conceito que poderiam ser aprimoradas.

No quinto dia do curso, para o desenvolvimento do Bodystorming, a palestrante solicitou que todas as equipes revisassem os principais aspectos dos conceitos do PSS que derivaram dos dias anteriores (detalhamento dos problemas, requisitos e unidade de satisfação). Solicitou ainda que os alunos pensassem no script para representação dos conceitos em cenas. A Figura 5, a seguir, demonstra a ficha de script preenchida pelos estudantes que orientaram esta atividade. $O$ foco do Bodystorming foi à geração de alternativas e a interação com conceitos gerados nas aulas anteriores.

Figura 5 -Pré Script das cenas/conceitos escolhidos para a geração de alternativas.

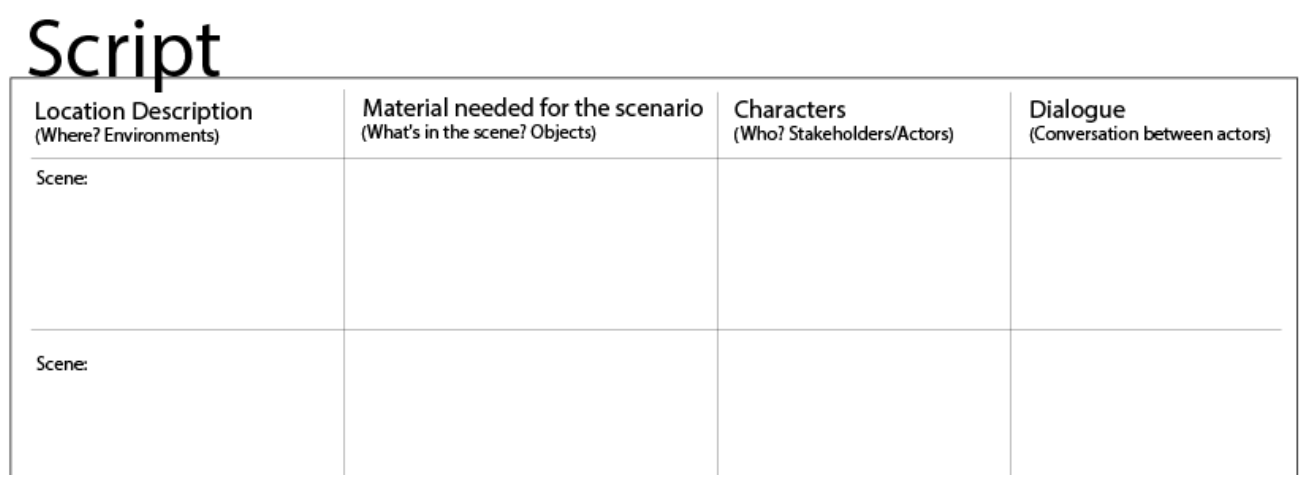

Fonte: Os autores (2017) 
Sob a perspectiva do Bodystorming como uma ferramenta criativa, talvez uma das suas maiores vantagens seja o fato de trazer para as atividades ideais um grande aliado do pensamento criativo: o jogo e a brincadeira. $O$ jogo entra em vigor ao explorar novas ideias, abraçando o pensamento divergente e lateral; permitindo uma experiência prática na construção do conjunto para representação de ideias; usando o papel para estimular o designer a se colocar na perspectiva das partes interessadas (SEGURA \& VIDAL, 2016).

O Bodystorming possibilita a simulação do ambiente onde o serviço real ocorrerá e reduz a carga de trabalho cognitiva que seria exigida se as atividades dependerem da memória do participante e da criatividade. A prototipagem do cenário estimula os participantes a recuperarem memórias pessoais relevantes, facilitando o reconhecimento de analogias e direcionando a atenção para características importantes das ideias (OULASVIRTA et al., 2003).

O contato com o cenário real também seria importante, no entanto não é incomum que esse ambiente não seja fisicamente acessível (ex: casas particulares), nem socialmente acessível (a presença real de um pesquisador pode mudar a atividade estudada) ou mesmo não eticamente acessível (ex: centros de saúde). Nesses casos, a simulação pode ser a única opção (OULASVIRTA et al, 2003) e isto ocorreu neste estudo de caso. Os alunos usaram a sala de aula em si e um Laboratório de Fotografia para preparar o estágio de sua sessão de Bodystorming (Figura 6).

Figura 6 - Vídeo e foto de bodystorming realizado

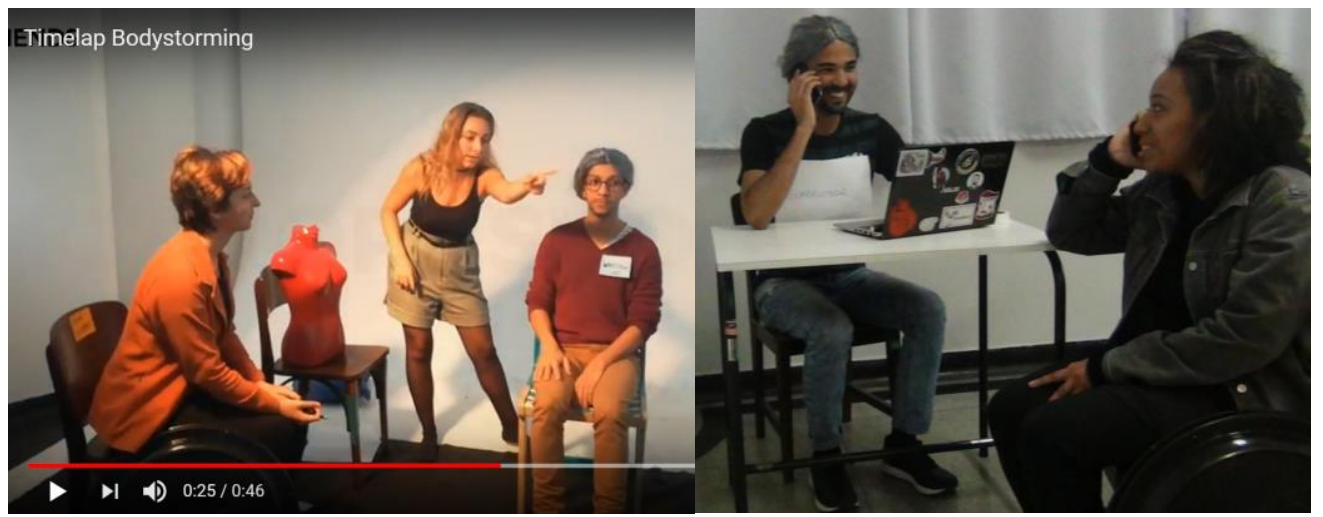

Fonte: vídeo disponível em: <https://www.youtube.com/watch?v=36dC6ZZT9EA> (2017)

Nenhum dos alunos tinha experiência de atuação anterior. Para apoiar a construção do cenário foram incorporados artefatos regulares de uma sala de aula e do laboratório de fotografia, como cadeiras, lâmpadas, fitas, etc. Apesar disso, a aplicação desta ferramenta mostrou-se útil na criação e teste de cenários possíveis.

Devido a restrições logísticas, a visita a pessoas em cadeira de rodas ocorreu apenas após a sessão do bodystorming. Assim, uma maior empatia com o desafio proposto pela disciplina, antes da fase de ideação, dependia fortemente das próprias iniciativas dos alunos para entrar em contato direto com pessoas em cadeira de rodas.

Os conceitos gerados ao final da disciplina por cada equipe são brevemente descritos no Quadro 2 a seguir: 
Quadro 2 - Síntese do conceito de PSS final gerado por cada equipe

\begin{tabular}{|c|c|c|}
\hline Temas & Conceito Principal & Imagens ilustrativas \\
\hline $\begin{array}{l}\text { Moda (Instituto } \\
\text { Amanda Lyra) }\end{array}$ & $\begin{array}{l}\text { Proposta: Oferecer uma plataforma para a fabricação } \\
\text { de moda casual para pessoas em cadeiras de rodas } \\
\text { (residentes de Curitiba, homens e mulheres de } 20 \text { a } \\
40 \text { anos) como forma de fazer roupas acessíveis com a } \\
\text { oportunidade de fabricá-las e personalizar através da } \\
\text { modelagem e tutorial de opensource. }\end{array}$ & Fonte: Equipe 01 \\
\hline $\begin{array}{l}\text { Entretenimento } \\
\text { (Teatro e cinema } \\
\text { acessível) }\end{array}$ & $\begin{array}{l}\text { Proposta: Serviço que possibilite uma experiência } \\
\text { cultural mais inclusiva aos cadeirantes, seu objetivo é } \\
\text { auxiliar que o usuário de cadeira de rodas tenha } \\
\text { acesso a entretenimento cultural personalizado, } \\
\text { inclusivo e proveitoso por meio da adaptação do } \\
\text { espaço - conforme a demanda. O serviço inclui o } \\
\text { cuidado e acompanhamento do cadeirante desde a } \\
\text { compra do bilhete até o retorno para a casa. }\end{array}$ & 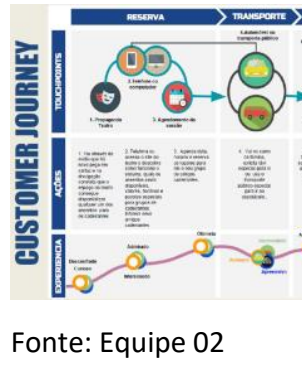 \\
\hline $\begin{array}{l}\text { Mobilidade (Feira em } \\
\text { roda) }\end{array}$ & $\begin{array}{l}\text { Proposta: Empresa desenvolve feiras de serviços em } \\
\text { parques públicos, com foco em usuários de cadeira de } \\
\text { rodas e as pessoas mais próximas (por exemplo, } \\
\text { membros da família) para promover redes e } \\
\text { companheirismo através de oficinas de manutenção } \\
\text { das cadeiras de rodas dentro de uma instalação } \\
\text { móvel. Principal valor a ser trabalhado no serviço: } \\
\text { companheirismo. }\end{array}$ & Fonte: Equipe 03 \\
\hline $\begin{array}{l}\text { Cadeirantes } \\
\text { Adquiridos (SICA - } \\
\text { Serviços Integrados } \\
\text { para Cadeirantes } \\
\text { Adquiridos) }\end{array}$ & $\begin{array}{l}\text { Proposta: Desenvolver sistemas de integração de } \\
\text { serviços para ajudar cadeirantes adquiridos na } \\
\text { adaptação de sua rotina, oferecendo segurança e } \\
\text { independência. O conceito principal da alternativa é } \\
\text { vincular ao plano de saúde treinamentos para o } \\
\text { cadeirante adquirido, possibilitando que este } \\
\text { compartilhar dificuldades encontradas na realização } \\
\text { de atividades e saiba como melhor supera-las. }\end{array}$ & Fonte: Equipe 04 \\
\hline
\end{tabular}

Fonte: participantes da disciplina (2017)

Após definição do conceito final pelas equipes, estes foram apresentados e avaliados por cadeirantes. A resposta dos usuários aos conceitos foi muito positiva, e demonstrou que os conceitos atendem a demandas reais, destaca-se a seguir alguns dos comentários realizados por uma das cadeirantes:

\footnotetext{
" [Tema Entretenimento] Achei simples e eficaz a ideia, já aumentaria muito o perímetro que os cadeirantes poderiam ocupar e ter seu acompanhante por perto! Ótima sacada! É realmente complicado assistir a um filme ou peça/show sem ter conforto, sem curtir [...] o que rola hoje é acessibilidade medíocre para que quem projetou e os donos fingirem que tem a consciência limpa [...] o projeto de vocês traz a verdadeira ideia de acessibilidade! Parabéns!"
} 


\begin{abstract}
"[Tema Moda]: Para as mulheres em especial... Viemos de uma sociedade que impõe padrões desde que nascemos e tão comum a nossa autoestima ser mais baixa que uma cratera... traz muito mais do que costurar pedaços de pano.. traz a interação. Traz cor, mobilidade, modernidade e inspirações de outros cadeirantes e todos os deficientes que podem compartilhar suas vitórias.

"[Tema Feira em roda]: Maravilhoso isso! Fácil de colocar em prática posso ajudar no que precisar, já estou com uma parceria com a Secretaria do Direito da Pessoa com Deficiência e acho que ajudaria imensamente as pessoas que estão passando por dificuldades de adaptação! Poderia também haver uma parte cultural, convidando algum artista para encerrar, como uma grande festa mesmo, para mostrar que o mundo não acabou, e sim um mundo novo apareceu, cheio de coisas a serem desbravadas e que com ajuda fica mais fácil e pode ser divertido! Poderia ter um stand com as roupas do instituto também!"
\end{abstract}

(Amanda Lyra - Cantora, 27anos - 2017) Nasceu com atrofia muscular espinhal e por conseqüência da doença usa atualmente cadeira de rodas.

\title{
4.1 Aplicação de Questionário
}

Para avaliação das ferramentas de criatividade foi elaborado um questionário com dez perguntas de múltipla escolha nas quais os estudantes obrigatoriamente deveriam justificar cada escolha realizada. O questionário elaborado obteve resposta de onze dos doze estudantes que participaram de todas as atividades propostas pela disciplina.

Além das ferramentas direcionadas às duas sessões de criatividade, observou-se que as demais ferramentas aplicadas na disciplina também foram importantes para o processo criativo. Por exemplo, a ferramenta SDO (Sustainable Design Orienting Toolkit - Kit de Ferramentas de Orientação de Design Sustentável) aplicada na disciplina para a aproximação dos estudantes com o problema a ser estudado, e não de fato para criação, foi considerada uma das que mais auxiliou no processo criativo. Os estudantes justificam a escolha devido aos diversos princípios, check-lists e exemplos existentes dentro da plataforma da ferramenta online.

Desta forma, a fim de entender a percepção dos estudantes com relação às ferramentas utilizadas durante o curso, as perguntas envolveram não apenas as três ferramentas de criatividade direcionadas as sessões de criação, mas todas as demais ferramentas aplicadas na disciplina. O gráfico a seguir mostra as ferramentas consideradas pelos estudantes como principais para o processo criativo (Gráfico 1).

Gráfico 1 - Ferramentas que mais auxiliaram na etapa de criatividade de acordo com estudantes.
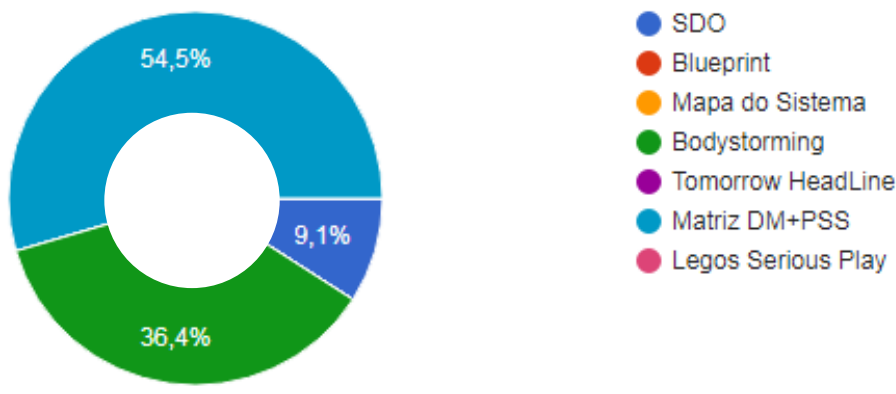

Fonte: Os autores (2017) 
Em primeiro lugar ficou a ferramenta de Matriz DM+PSS (54,5\% - 6 estudantes), seguida do Bodystorming (36,4\% - 4 estudantes) e SDO (9,1\% - 1 estudante). Os estudantes justificam a escolha destacando que a Matriz DM+PSS, foi a que possibilitou a geração de alternativas com maior detalhamento e definição pela equipe. Outros afirmam ainda que a ferramenta ajudou a pensar "fora da casinha" e ter ideias "inusitadas" para o projeto. Os exemplos presentes nos 35 cartões da ferramenta também foram considerados de grande ajuda na geração de alternativas. No entanto alguns estudantes destacam que nem sempre os exemplos pareciam se encaixar na realidade proposta pela disciplina.

A ferramenta de bodystorming, posicionada em segundo lugar, foi descrita pelos estudantes como de rápido entendimento e utilização, possibilitando uma maior compreensão do cenário real:

\footnotetext{
"A ferramenta obriga a pensar em soluções para um problema enquanto ele acontece diante do seus olhos...te tendo como participante ativo da experiência. É o seu olhar que se transforma no do usuário e stakeholders. Fora isso, ainda é possível enxergar se uma solução pensada no papel seria possível de aplicar na vida real (Estudante 01, 2017)."
}

A ferramenta SDO, se destaca na percepção dos alunos por possibilitar questionamentos com relação à sustentabilidade que passariam despercebidos no processo de criação do conceito. No entanto, a SDO: também ficou em segundo lugar em ordem de complexidade em ser aplicada, os estudantes destacaram que o site não é muito intuitivo o que dificulta também o uso $(36,4 \%$ - 4 estudantes) (Gráfico 2)

Gráfico 2 - Ferramentas de maior complexidade na aplicação de acordo com estudantes.

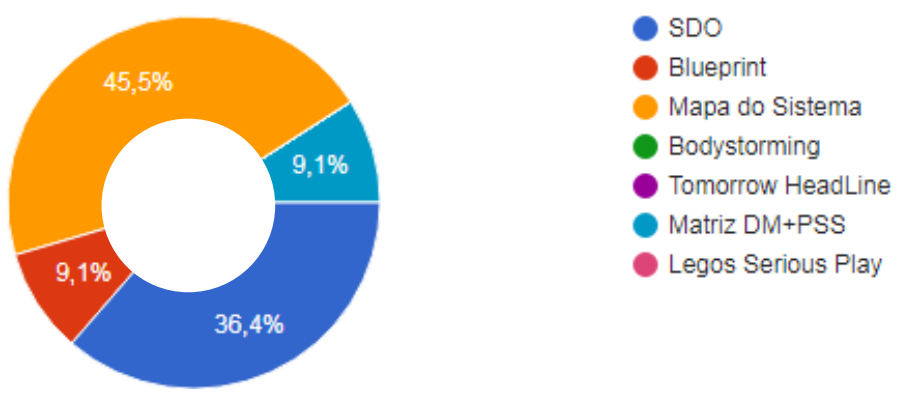

Fonte: Os autores (2017)

A ferramenta de mapa do sistema foi considerada a de maior dificuldade em ser aplicada (45,5\% - 5 estudantes): "A maior dificuldade foi entender o processo por inteiro, levando em consideração todos os stakeholders mesmo, não só aqueles diretos que são mais fáceis de notar, e depois alinhar todas as relações entre cada um desses personagens em um mapa só, de forma que fosse inteligível (estudante)".

A fim de entender a necessidade de melhorias nas ferramentas para a etapa de criação, os estudantes foram questionados quanto à necessidade de adição de exemplos e princípios que indicassem 'caminhos de referência (passo-a-passo com exemplos para aplicação das ferramentas)'. Todas as respostas foram positivas e alguns estudantes justificaram que: 


\begin{abstract}
"Sim, com certeza. Acho que um dos fatores que ajudou a fazer da Matriz DM + PSS a ferramenta que mais ajudou no nosso processo criativo foi realmente ter exemplos nos cartões, que não só norteavam o processo de pensar na ideia de acordo com as restrições propostas em cada cartão, mas também trazia exemplos de serviços que funcionavam sob aquelas restrições, então por vezes, nossas ideias na ferramenta forma meras adaptações do que ali já estava proposto, o que certamente facilitou a entender o processo e permitiu que mais ideias fossem criadas (Estudante 02, 2017)."

“Com toda certeza ajudaria na compreensão da ferramenta, isso facilitaria na execução reduzindo o tempo e quantidade de inúmeras explicações extras e desgaste e frustração dos alunos ao utiliza-las (Estudante 03, 2017)."
\end{abstract}

Com relação à complexidade de determinadas ferramentas, os estudantes destacaram ainda o pouco tempo direcionado para entendimento e aplicação destas: "Como a disciplina teve apenas duas semanas, entendo que o tempo para a aplicação das ferramentas era curto. Gostei de todas, mas gostaria de talvez ter aplicado apenas parte delas, para dedicar mais tempo a cada uma (Estudante)" [...]"Acredito que há a necessidade de melhor uso do tempo, mais contato com o usuário em sala (Estudante)"

Os estudantes ranquearam ainda as ferramentas de acordo com afinidade no momento de utilização. A ferramenta Lego Serious Play obteve o primeiro lugar (45,4\% - 5 estudantes), seguida do Bodystorming (27,3\% - 3 estudantes), Matriz DM+PSS (18,2\% - 2 estudantes) e a Jornada do Usuário (Customer Journey, com 9,1\% - 1 estudante).

Gráfico 1 - Afinidade dos estudantes com as ferramentas aplicadas.
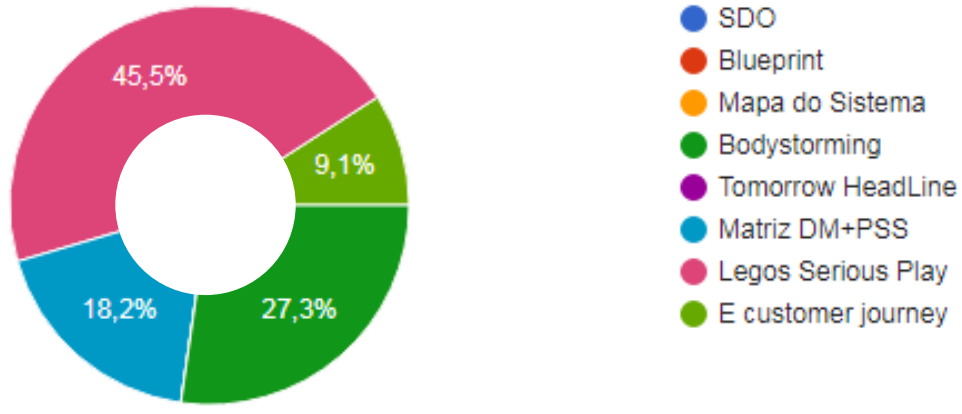

Fonte: Os autores (2017)

A interatividade e possibilidade de visualizar e alterar facilmente o cenário do PSS com o Lego Serious Play fez com que a maior parte dos estudantes tivesse uma maior afinidade com a ferramenta: "Foi muito mais fácil de visualizar e modificar o serviço que estávamos projetando por meio dessa ferramenta"[...] "Ferramenta dinâmica e estimulante para a geração de ideias."

A aplicação do Lego Serious Play ocorreu em três ciclos: a) Construção do cenário do conceito; b) Intervenção no conceito de outro grupo (uso de post-its com questionamentos e direcionamentos do cenário montado com o lego); c)Finalização do conceito. Os estudantes consideraram, em sua maioria, positivo o uso de post-its na ferramenta: "No Lego Serious Play os post-its funcionaram como 'memory cards' para as partes do processo que precisavam ser melhoradas ou alteradas, a partir dos comentários durante as apresentações".

No Bodystorming não foram entregues cartões que direcionassem o uso da ferramenta e o processo de criação dos estudantes (exemplos de possíveis cartões: "a) Acessibilidade : Use rampas de fácil acesso e possibilite a customização do espaço"; "b) Cordialidade: Disponibilize 
acompanhantes que busquem os cadeirantes no carro;"). No entanto os estudantes ao serem questionados sobre a necessidade destes para auxiliar no processo criativo, em sua maioria responderam de forma positiva, apenas um estudante ressalta que os cartões poderiam limitar o processo criativo : "Acho que isso deixaria um pouco "preso" no exemplo do cartão. Mas não tenho certeza."

Como conclusão do questionário os alunos puderam escrever, de forma discursiva e opcional, sugestões para as disciplinas futuras:

"Como a proposta é de duas semanas, talvez exemplos da aplicação de cada ferramenta tornassem o tempo que as equipes levaram em cada etapa mais eficiente (Estudante 04, 2017)."

"Mais tempo para as pesquisas e entrevistas com os usuários, claro que tivemos alguns imprevistos que nos atrapalharam nesse quesito, mas acho que a programação do curso podia delegar mais tempo para essa etapa, já que esse é o público que queremos ajudar (Estudante 05, 2017)."

\section{Conclusões e Discussões}

Tem-se um desafio voltado ao desenvolvimento de estratégias e ferramentas que deem suporte ao processo criativo do PSS (Product-Service-System), guiando projetistas para espaços de soluções diversas, explorando ideias mais criativas e de elevado potencial de inovação.

Observou-se no resultado do questionário que as ferramentas que aplicavam exemplos, partem na frente no sentido de criação das ideias e facilidade de compreensão da ferramenta por terem exemplos de boas práticas já aplicadas anteriormente. No entanto entende-se também a necessidade e importância do processo de analogia e abstração a fim de não se ficar preso na mesma ideia existente.

O Curso Piloto demonstrou a importância das ferramentas para a geração de alternativas criativas e consistentes. O acumulo conceitual que ocorreu no decorrer de cada dia com as ferramentas proporcionou claramente maior confiança aos alunos para gerar uma variedade de ideias, com um entendimento adequado sobre o problema e possíveis cenários de soluções. 0 feedback dos cadeirantes demonstrou a coerência nas alternativas geradas, mesmo que estas ainda se encontrem em estágio embrionário.

O uso destas ferramentas propiciou uma maior colaboração entre os estudantes de design, professores e usuários cadeirantes. Futuras iniciativas devem ser realizadas a fim expandir o estudo e aumentar a confiabilidade da pesquisa. Averiguando-se também a necessidade de incluir exemplos e princípios em ferramentas de criatividade que possam ser aplicados como modelo de referência na geração de PSSs mais criativos.

\section{Referências}

CHU, Y.; LI, Z.; SU, Y.; PIZLO, Z. Heuristics in Problem Solving: The Role of Direction in Controlling Search Space. The Journal of Problem Solving, v. 3, n. 1, p. 27-51, 2010.

KIM, K. J., LIM, C. H., LEE, D. H., LEE, J., HONG, Y. S., \& PARK, K. A concept generation support system for product-service system development. Service Science, v. 4, n. 4, p. 349-364, 2012. 
MANZINI, E.; VEZZOLI, C. Product-service systems and sustainability: Opportunities for sustainable solutions. Unep, 2002.

MARILUNGO, E., COSCIA, E., QUAGLIA, A., PERUZZINI, M., \& GERMANI, M. (2016). Open Innovation for ideating and designing new Product Service Systems. Procedia CIRP, v. 47, p. 305310, 2016

OSTROM, A. L; , BITNER, M. J.; BROWN, S. W.; BURKHARD, K. A.; GOUL, M.; SMITH-DANIELS, V.; DEMIRKAN, H.; AND RABINOVICH, E. Moving Forward and Making a Difference: Research Priorities for the Science of Service. Journal of Service Research, 13(1) 4-36, 2010.

OULASVIRTA, A.; KURVINEN, E. \& KANKAINEN, T. Understanding contexts by being there: case studies in bodystorming. Ubiquit Comput (2003) 7: 125-134 DOI 10.1007/s00779-003-0238-7

PINHANEZ, C. Educação e Pesquisa em Ciência de Serviços no Brasil: Necessidades e Oportunidades. Revista de Educação Superios do SENAC, v. v. 2, n. n. 2, p. p. 37-53, 2009. Disponível em: <http://www.pinhanez.com/claudio/publications/competencia 09.pdf> Acesso em 15/07/2017.

POLAINE, A.LOVLIE, L.; REASON, Ben. Service design. From Implementation to Practice. New York: Rosenfeld Media, 2013.

RODRIGUEZ, J.; DIEHL, J.C. \& CHRISTIAANS, H. Gaining insight into unfamiliar contexts: A design toolbox as input for using role-play techniques. Interacting with Computers 18 (2006) 956-976

SACO, R. M.; GONCALVES, A. P. Service design: An appraisal. Design management review, v. 19, n. 1, p. 10-19, 2008.

SANTOS, A. dos ; SILVEIRA, E. L. ; GARCIA, A. M. ; CARNEIRO, M. A. . Bodystorming: lessons learnt from its use on the classroom. In: ServDes2018 - Service Design Proof of Concept., Milano. Annali ServDes, 2018.

SDO-MEPSS. Design-Orienting Toolkit. Disponível em: <http://www.mepsssdo.polimi.it/mepss/website/mepss.html> Acesso em: 06 dez.2017.

SEGURA, E. M.; VIDAL, L. T. Bodystorming for Movement-based Interaction Design. Human Technology. Volume 12(2), November 2016, 193-251 DOI: http://dx.doi.org/10.17011/ht/urn.201611174655.

SERVICE DESIGN NETWORK. 2015. What is Service Design? Disponível em: http://www.serviceDesign-network.org/intro/. Acesso em: 29 nov.2017.

SILVA, M. J. V., SILVA FILHO, Y. V., ADLER, I. K., LUCENA, B. F., \& RUSSO, B. Design thinking: Inovação em negócios. Rio de Janeiro: MJV, 2012.

TUKKER, A. Eight types of product-service system: eight ways to sustainability? Experiences from SusProNet. Business strategy and the environment, v. 13, n. 4, p. 246-260, 2004.

TUKKER, A.; TISCHNER, U. Product-services as a research field: past, present and future. Reflections from a decade of research. Journal of cleaner production, v. 14, n. 17, p. 1552-1556, 2006.

YIN, R. K. Case study research: Design and methods (3rd ed.). Thousand Oaks, CA: Sage, 2003. 